\title{
O uso das tecnologias assistivas na mediação da informação em biblioteca escolar: acessibilidade para alunos com deficiência visual
}

\author{
The use of assistive technologies in mediation of information in school library: accessibility \\ for visually impaired students
}

Ana Cristina de Almeida Costa Mestranda em Ciência da Informação pela Universidade Federal do Pará - UFPA, Brasil. Bibliotecária-documentalista da Universidade Federal do Pará - UFPA, Brasil. E-mail: anacris@ufpa.br

Tania Chalhub

PhD Social Work - University of Minnesota, EUA. Professora do Programa de Pós-Graduação em Ciência da Informação da Universidade Federal do Pará - UFPA, Brasil.

E-mail: chalhubtania@gmail.com

\section{Resumo}

A biblioteca escolar é fundamental no apoio pedagógico de alunos, independente das suas demandas comunicacionais. É essencial que a biblioteca como um ambiente educacional ofereça acessibilidade a todos os seus usuários, oferecendo materiais educacionais adequados a todos. Desse modo, o estudo de usuários se torna significativo para conhecer as principais características dos usuários, visando a oferta de produtos e processos que possibilitem a mediação da informação para usuários com deficiência. Este artigo buscou identificar os recursos para acesso e uso por pessoas com deficiências visuais nas bibliotecas. O objetivo principal é discutir a literatura de Ciência da Informação sobre metodologias para acessibilidade de usuários com deficiência visual em bibliotecas escolares, visando contribuir com a inclusão eficaz desses usuários no meio informacional. Trata-se de uma revisão de literatura tendo como fonte a Base de Dados Referenciais de Artigos e Periódicos em Ciência da Informação (BRAPCI). Após identificar os estudos, descreve e discute as principais propostas acessíveis e inclusivas presentes que podem ser utilizadas nas bibliotecas escolares, tais como: softwares gratuitos- NonVisual Desktop Access (NVDA), Dosvox, Macdayse, leitor de tela Jaws, Lupa, produção de livros digitais. Este estudo aponta para a necessidade de se conhecer as práticas inclusivas para que o acesso e uso da informação sejam garantidos de forma equitativa objetivando tornar a inclusão mais efetiva em bibliotecas escolares.

Palavras-chave: Tecnologia assistiva. Biblioteca Escolar. Inclusão. Deficiência visual. Mediação da informação.

\begin{abstract}
The school library is fundamental in the pedagogical support of students, regardless of their communicational demands. It is essential that the library as an educational environment offers accessibility to all its users, offering educational materials suitable for all. For this, the study of users becomes significant in order to know the main characteristics of users, aiming at offering products and processes that enable the mediation of information for users with disabilities. This article sought to identify the resources for access and use by people with visual impairments in libraries. The main objective is to discuss the Information Science literature on methodologies for accessibility of visually impaired users in school libraries, aiming to contribute to the effective inclusion of these users in the information medium. This is a literature review based on the Base de Dados em Ciência da Informação (BRAPCI). After identifying the studies, it describes and discusses the main accessible and inclusive proposals present that can be used in school libraries, such as: free software - NonVisual Desktop Access (NVDA), Dosvox, Macdayse, Jaws screen reader, Magnifier, book production digital. This study points to the need to know inclusive practices so that access and use of information is guaranteed in an equitable way aiming at making inclusion more effective in school libraries.
\end{abstract}

Keywords: Assistive technology. School library. Inclusion. Visual impairment. Information mediation.

Bibl. Esc. em R., Ribeirão Preto, v. 7, n. 2, p. 1-16, 2021.

DOI: 10.11606/issn.2238-5894.berev.2021.184665 
O uso das tecnologias assistivas na mediação da informação em biblioteca escolar: acessibilidade para alunos com deficiência visual

\section{Introdução}

Não há dúvidas de que a biblioteca escolar é um espaço de aprendizagem. Entretanto, para que esse papel seja desempenhado com eficiência há a necessidade de um trabalho em conjunto e multidisciplinar envolvendo: bibliotecários, pedagogos, professores e a direção da escola. Neste processo educacional o bibliotecário não deve estar isolado no espaço da biblioteca, mas sim desenvolver práticas em consonância com a equipe pedagógica.

Nessa direção Wellichan e Lino (2020) ressaltam que bibliotecários atuantes em biblioteca escolar devem interagir com os demais segmentos da escola, no sentido de se fazerem presente e mostrarem sua capacidade e importância como profissional que pode colaborar no processo de ensino e aprendizagem, sobretudo por disponibilizar meios para obtenção de informação e conhecimento.

Uma das principais atuações do bibliotecário no espaço escolar é junto a alunos com deficiência numa abordagem inclusiva. Segundo a Lei 13.146 de 06 de julho de 2015, "a pessoa com deficiência é aquela que tem impedimento de longo prazo de natureza física, mental, intelectual ou sensorial" (BRASIL, 2015, p. 1). Esta Lei, também conhecida como Lei Brasileira de Inclusão da Pessoa com Deficiência (LBI), ou Estatuto da Pessoa com Deficiência, é um marco nas questões relacionadas à inclusão de diferentes grupos sociais por estabelecer a importância da garantia e promoção de oportunidade e condições para que todos tenham os mesmos direitos e liberdades fundamentais da pessoa com deficiência, visando sua inclusão social e exercício da cidadania (BRASIL, 2015).

Nesse aspecto, no que concerne à biblioteca escolar, observa-se que ela tem por função contribuir para eliminar os entraves que podem limitar o acesso aos serviços informacionais. Visando a garantir que todos, sem distinção, exerçam seus direitos de acesso à informação de forma plena, com autonomia e compreensão, o bibliotecário possibilitará que os usuários da biblioteca possam se instrumentalizar via acesso à informação para participar ativamente da sociedade.

Assim, é imprescindível que os bibliotecários conheçam as diferentes categorias de deficiências para que possam buscar materiais em formato acessível que atenda às necessidades de seus usuários. No âmbito da Ciência da Informação (CI), a literatura apresenta avanços sobre a atuação do bibliotecário diante de usuários com deficiência (DINIZ; ALMEIDA; FURTADO, 
2017; HOTT; RODRIGUES; OLIVEIRA, 2018; CONTE; OURIQUE; BASEGIO, 2017), mas ainda há lacunas que precisam ser preenchidas como a relacionada a pessoas com deficiência visual em biblioteca escolar.

$\mathrm{Na}$ garantia de direitos às pessoas com deficiência visual, a biblioteca escolar deve buscar recursos que possam ser usados na mediação da informação para esses usuários. Nessa perspectiva este estudo parte da indagação sobre quais instrumentos estão sendo utilizados nas bibliotecas para mediação da informação aos usuários com deficiência visual. Dessa forma, o objetivo da pesquisa que originou este artigo foi examinar a literatura de Ciência da Informação buscando por metodologias e recursos que possibilitassem ampliar a acessibilidade de usuários com deficiência visual em bibliotecas escolares, tendo como fonte os artigos científicos indexados na Base de Dados em Ciência da Informação-BRAPCI.

O artigo terá como foco mediação da informação para usuário com deficiência visual e práticas de mediação para acessibilidade de pessoas com deficiência visual em biblioteca escolar.

\section{Mediação da informação para usuários com deficiência visual}

Para Almeida Júnior e Bortolin (2007), a mediação da informação é uma prática que inclui desde o armazenamento até ao processamento da informação, estando relacionada às principais atividades desenvolvidas pelo bibliotecário no que diz respeito à informação. Assim, a mediação da informação não é somente a transferência da informação para o usuário, mas se refere também a como o bibliotecário vai: realizar a política de desenvolvimento de coleções, pensar sobre quais as aquisições e materiais deverão fazer parte do acervo de modo que proporcione um atendimento de forma equitativa e planejar onde e como vai realizar o processamento técnico da informação. Além disso, inclui ainda os serviços de referência e informação, no qual os usuários (que são o foco da mediação) irão se apropriar da informação.

Silva, Duarte e Silva (2017) ressaltam a importância da comunicação e proatividade do bibliotecário. Para esses autores deve haver a ação mútua entre este profissional e o público, para que a mediação possa ser um contributo na construção do conhecimento deste usuário. Seguindo o pensamento de autores supracitados podemos também destacar que a mediação que ocorre nos serviços de informação e referência requer que o bibliotecário e sua equipe: possuam conhecimento do que seu público busca, tenham visão social e cultural, vão além de usar 
O uso das tecnologias assistivas na mediação da informação em biblioteca escolar: acessibilidade para alunos com deficiência visual

somente o que tem disponível na organização e busquem transferir a informação através de ações e eventos culturais.

Além disso, é importante acompanhar a evolução tecnológica e envolver a família dos alunos, no intuito de buscar apoio para realizar os projetos da biblioteca. Para Estabel e Moro (2011) a ligação entre escola, biblioteca e família através de suas diversas funções culturais e históricas torna a biblioteca um ambiente educacional de interação, compartilhamento e de comunicação na transmissão da informação.

Para a construção de todo esse processo informacional é extremamente importante saber quem são os usuários da biblioteca escolar, principalmente os alunos com necessidades especiais. Desse modo se torna imprescindível pensar em políticas de inclusão e buscar estratégias metodológicas de práticas mediacionais para o público com deficiência que frequenta a biblioteca. Essas atitudes são importantes para não cercear os direitos de obter a informação, mas sim torná-la acessível, possibilitando que cada aluno aprenda com autonomia.

Nesse aspecto, Marcolino e Castro Filho (2014) colaboram afirmando que a escola com a perspectiva da educação inclusiva precisa integrar o aluno a todas as práticas pedagógicas, e assim, será na biblioteca onde os alunos com deficiência participam e fazem uso de materiais adequados e serviços disponíveis para todos. Destaca-se que não basta inserir na escola comum o aluno com deficiência como sujeito passivo, mas é necessário reduzir as barreiras encontradas e oportunizar a eles agirem como sujeitos ativos.

\section{As tecnologias assistivas e as práticas de mediação em biblioteca escolar}

As tecnologias assistivas (TA) são importantes suportes para as pessoas com necessidades especiais. Santos e Carvalho (2020, p. 10) comentam que a TA "refere-se a um conjunto de serviços, produtos e ferramentas desenvolvidos através da tecnologia, para facilitar as atividades no cotidiano das pessoas com alguma limitação física, sensorial ou intelectual, e garantir a essas o máximo possível de autonomia”.

Para que as práticas de mediação para alunos com deficiência visual sejam bemsucedidas os bibliotecários necessitam utilizar recursos tecnológicos, específicos. No nosso caso estaremos priorizando as TA relacionadas a comunicação de pessoas com deficiências sensoriais, especificamente a visão. Entre as principais para uso em bibliotecas Fenandes e 
Ana Cristina de Almeida Costa e Tania Chalhub

Vianna (2016, p. 3) apontam algumas ferramentas próprias para os usuários com deficiência visual obterem a informação que precisam, sendo estas:

\begin{abstract}
Os sintetizadores de voz, que promovem o processo de produção artificial de voz humana. São sistemas informatizados e podem ser implementados por software ou hardware. Um sistema texto-voz (ou TTS, em inglês) converte textos em linguagem escrita para voz; outros sistemas interpretam a representação linguística simbólica (transcrição fonética) em voz. Acerca das vantagens dos sintetizadores de voz, destacam-se que os sistemas de saída de voz podem ser acessados por usuários com qualquer tipo de deficiência visual, os mesmos podem ser compartilhados com usuários sem deficiências, facilitando o trabalho em grupo, a interação e o apoio pedagógico, dentre outras possibilidades.
\end{abstract}

Nessa perspectiva, Alves, (2017) acrescenta que as bibliotecas podem usar o Sistema Braille, o livro em braile, o livro em braille e tinta, leitor de tela, ampliador de tela, a audiodescrição, bem como os recursos ópticos, os livros acessíveis: audiolivro, livro com fonte ampliada, livro digital Daisy, livro digital em texto, reglete, punção, máquina de escrever e impressora em Braille, o sorobã e as lupas.

De acordo com Pinheiro e Oliveira (2018), além de conhecer o público da biblioteca, o bibliotecário e sua equipe devem saber como fazer a interferência e quais tecnologias devem utilizar para atender as demandas de acessibilidade informacional de cada usuário. Portanto, é preciso que esses profissionais também possuam habilidades para utilizar os equipamentos e sistemas envolvidos.

A partir dos dados apresentados observa-se vários tipos de recursos, sendo que algumas destas tecnologias são de baixo custo, outras oferecidas de forma gratuita e que podem ser adquiridas pelas bibliotecas para se adequarem ao mínimo que seja na construção de ações que favoreçam de fato a inclusão.

\title{
4. Metodologia
}

Como procedimento metodológico foi realizada uma revisão de literatura para discutir o que vem sendo proposto nos estudos de Biblioteconomia e Ciência da Informação para mediação da informação do público em questão.

A revisão de literatura é um procedimento que consiste no levantamento e análise do que já foi publicado sobre o tema e o problema de pesquisa escolhido. Além disso, permite um mapeamento de quem já escreveu e o que já foi escrito sobre o tema e/ou problema da pesquisa (SILVA; MENEZES, 2001). 
O uso das tecnologias assistivas na mediação da informação em biblioteca escolar: acessibilidade para alunos com deficiência visual

A pesquisa foi realizada no período de 19 a 26 de novembro de 2020, na Base de Dados Referenciais de Artigos e Periódicos em Ciência da Informação (BRAPCI) com recorte temporal entre os anos de 2010 e 2020. A busca foi feita por texto completo, título, palavrachave e resumo em todos os descritores escolhidos, para maior recuperação.

Tabela 1 - Dados quantitativos de descritores recuperados

\begin{tabular}{l|r|r|r|r}
\hline Descritores & \multicolumn{1}{|l|}{ Títulos } & Palavras-chave & \multicolumn{1}{|c|}{ Resumos } & Texto completo \\
\hline Deficiência visual & 22 & 16 & 60 & 66 \\
\hline Tecnologia assistiva & 18 & 33 & 34 & 183 \\
\hline $\begin{array}{l}\text { Tecnologia assistiva em } \\
\text { biblioteca }\end{array}$ & 8 & & 14 & 118 \\
\hline $\begin{array}{l}\text { Pessoas com deficiência } \\
\text { visual na biblioteca }\end{array}$ & 1 & 3 & 4 & 105 \\
\hline $\begin{array}{l}\text { Tecnologia Assistiva and } \\
\text { biblioteca }\end{array}$ & 1 & & & 24 \\
\hline
\end{tabular}

Fonte: Dados da pesquisa (2020)

Foi feita a leitura dos resumos e leitura do texto completo quando não se identificava o tema no resumo. Foram recuperados em toda busca um total de 183 artigos em texto completo dos quais 168 foram descartados por não estarem condizente com o objeto de estudo. Dessa forma o corpus da pesquisa limitou-se a 15 artigos.

Para análise foram selecionados somente os estudos que trazem referência à acessibilidade em bibliotecas físicas para pessoas com deficiência visual e considerados com informações pertinentes para extrair recursos que consideramos ter menor custo-benefício no que se refere à mediação da informação para alunos com deficiência visual na biblioteca escolar, embora os demais recursos apresentados possam ser usados em bibliotecas escolares, desde que haja investimento na instituição.

\section{Resultados e discussões}

A literatura aponta diversos estudos que apresentam práticas que vêm sendo realizadas nas mais diversas bibliotecas para atender usuários com deficiência visual. Essas práticas foram identificadas nesta pesquisa e estão reunidas no quadro 1. Os dados da pesquisa foram organizados segundo a autoria e o tipo de recurso para possibilitar acessibilidade às pessoas com deficiência visual. 
Ana Cristina de Almeida Costa e Tania Chalhub

Quadro 1 - Recursos de Tecnologias assistivas apresentadas nas publicações indexadas na BRAPCI

\begin{tabular}{|c|c|}
\hline AUTORES & $\begin{array}{l}\text { RECURSOS DE ACESSIBILIADE PARA PESSOAS COM } \\
\text { DEFICIÊNCIA VISUAL }\end{array}$ \\
\hline $\begin{array}{l}\text { SILVA e BARBOSA } \\
\text { (2011) }\end{array}$ & $\begin{array}{l}\text { Livros em Braille e ampliados, os livros falados, gravação de texto em CD e } \\
\text { K7, digitação de texto em braile, impressora braille ampliadores de tela, } \\
\text { computadores com kit-multimídia, Programa Daisy e Open Book. Sistema } \\
\text { de painel Braille, Sistema com síntese de voz: Jaws, Virtual Vision, } \\
\text { DOSVOX, Dolphin, Slimware Window Bridge, Windows-Eyes. Sistemas de } \\
\text { ampliação: Dolphin, SmartView, Magic, LentePro. }\end{array}$ \\
\hline $\begin{array}{l}\text { FIALHO e SILVA } \\
\text { (2012) }\end{array}$ & $\begin{array}{l}\text { Máquina e impressora e livro em braile, solicitação de pesquisas por e-mail } \\
\text { utilizando o programa Jaws, produção de livros digitais a partir de obra } \\
\text { impressa por escaneamento com OpenBook, Zoom Text (programa que } \\
\text { aumenta tela) computadores com acesso à internet. Livros falados e os } \\
\text { softwares: DOSVOX -Delta Talk, Virtual Vision, Jaws, Magic,Mecdaisy o } \\
\text { Openbook. Controle de iluminação transmissão da luz com lentes absortivas, } \\
\text { controle da reflexão com tiposcópio, lápis 6B, lupa eletrônica. }\end{array}$ \\
\hline GONÇALVES (2012) & $\begin{array}{l}\text { Braille, Leitores de tela. O NonVisual Desktop Access - NVDA, o Jaws, } \\
\text { recursos que usam sintetizador de voz como o Open Book, Magic, Virtual } \\
\text { Vision, Dosvox que gratuito, MecDayse também gratuito. Lupa manual ou } \\
\text { eletrônica. Recursos não ópticos: lápis } 6 \mathrm{~B} \text { ou 3B. canetas hidrográficas que } \\
\text { aumentam contraste. Serviços de audiodescrição. }\end{array}$ \\
\hline POTY et al & $\begin{array}{l}\text { Pisos táteis direcionais, sinalização em Braille em locais de circulação. } \\
\text { Acervo em Braille. Máquina de escrever em Braille, impressora Braille, livro } \\
\text { digital, áudio livro, livro falado, softwares específicos para deficientes } \\
\text { visuais, leitores de tela, sintetizadores de voz o Dosvox, o Virtual Vision, } \\
\text { uso de software gratuitos. }\end{array}$ \\
\hline STORTI & $\begin{array}{l}\text { Leitores autônomos, Scanner (OCR), Leitor portátil de livros, Lupa } \\
\text { eletrônica, Linha braille, Software leitor de Tela, piso podotátil, sinalização } \\
\text { em braile, totem com planta da biblioteca acessível }\end{array}$ \\
\hline MELO (2015) & $\begin{array}{l}\text { Livros acessíveis: livro digital (cópia de livro impresso para arquivo de } \\
\text { computador; Livros formatados para impressão Braille, Áudio livros: são } \\
\text { livros gravados (voz humana) em fita magnética, CD, DVD ou MP3, Livros } \\
\text { no formato Daisy reproduzido pelo software Mecdaisy com distribuição } \\
\text { gratuita, Livros com letras ampliadas: livro convencional, ou digital, livro } \\
\text { digital em texto. Ampliador de tela (lupa), impressora em braile, bengala } \\
\text { dobrável, scaner leitor de imagem, software leitores de tela e ampliadores } \\
\text { (Jaws, NVDA, Dosvx, Zoom text.) máquina Perkins Braile, calculadora } \\
\text { sonora, reglete, punção, globo tátil, sorobã, colmeia para teclado. }\end{array}$ \\
\hline $\begin{array}{l}\text { FERNANDES e } \\
\text { VIANNA (2016) }\end{array}$ & $\begin{array}{l}\text { Ampliadores de tela, sintetizadores de voz, impressoras e conversores } \\
\text { braille, livros em disquetes ou cd-rom, livros digitalizados em formato } \\
\text { alternativo; criação e manutenção de sites que possibilitem a navegação, } \\
\text { utilização de serviços, acesso às informações e às interfaces gráficas na } \\
\text { internet, criação de bibliotecas virtuais com acervo diversificado e acessível } \\
\text { aos leitores, softwares de leitura de tela que utilizam os sintetizadores de voz }\end{array}$ \\
\hline $\begin{array}{l}\text { MALHEIROS e } \\
\text { CUNHA (2018) }\end{array}$ & $\begin{array}{l}\text { Braille, ampliação de tela, softwares Dosvox, Virtual Vision, magic, } \\
\text { MecDayse, Delt Talk, Dspeech, leitores de tela e síntese de fala, materiais } \\
\text { especiais em formato tradicional, como braile, livros falados em áudio e } \\
\text { livros ampliados, descrição de imagens, recursos de software são os leitores } \\
\text { de tela ou sintetizadores de voz, a ampliação de tela e o contraste, impressora }\end{array}$ \\
\hline
\end{tabular}

Bibl. Esc. em R., Ribeirão Preto, v. 7, n. 2, p. 1-16, 2021. 
O uso das tecnologias assistivas na mediação da informação em biblioteca escolar: acessibilidade para alunos com deficiência visual

\begin{tabular}{|c|c|}
\hline & $\begin{array}{l}\text { em relevo, ou thermoform, leitor de tela, detector de luminosidade, caneta } \\
\text { para desenho em relevo, audiodescrição, audiolivro, ledor, rotuladora braile, } \\
\text { máquina datilografia braile, sistema Dosvox, softwares LianeTTS, } \\
\text { VoiceOver; ZoomText, ferramentas Talks\&Zooms e Google Talk Back }\end{array}$ \\
\hline $\begin{array}{l}\text { OLIVEIRA e SILVA } \\
(2015)\end{array}$ & $\begin{array}{l}\text { Livros em braile e audiolivro, computadores com programas específicos e } \\
\text { sistemas especializados }\end{array}$ \\
\hline ALVES (2017) & $\begin{array}{l}\text { Sistema Braille, Livro em Braille e tinta, Leitor de tela, ampliador de tela, } \\
\text { Audiodescrição, Recursos ópticos (alto contraste, caracteres ampliados etc.), } \\
\text { audiolivro, Livro com fonte ampliada, Livro digital Daisy, Livro Digital em } \\
\text { Texto, Reglete, Punção, Máquina de escrever em Braille, Impressora em } \\
\text { Braille, Sorobã, Lupas }\end{array}$ \\
\hline ARAÚJO (2017) & $\begin{array}{l}\text { Tecnologias assistivas para acessibilidade do livro, livros em braile, livros } \\
\text { de letras ampliadas, livros falados, e-books e livros no formato Daisy. } \\
\text { Descrição de imagem, Uso de tecnologias assistivas Virtual Vision, Dosvox. } \\
\text { O MecDaisy com programa que permite para acesso ou criação de livros em } \\
\text { formato digital acessível e reprodução em áudio e textos acessíveis. Tocador } \\
\text { MecDaisy usado para tocar livro no formato Daisy. Texto acessível usando } \\
\text { o MecDaisy Sistemas operacionais, utilizados nos computadores e laptops, } \\
\text { tablets e smartphones. }\end{array}$ \\
\hline $\begin{array}{l}\text { MATOS, LEMOS e } \\
\text { SILVA (2017) }\end{array}$ & $\begin{array}{l}\text { Impressora braille, alfabeto braille, regletes, tabletes com aplicativos de } \\
\text { acessibilidade, bengala, dominó braile, scanner de voz, lupa eletrônica, } \\
\text { teclado colmeia, acionador de pressão, Placas de sinalização, Piso tátil, } \\
\text { direcional e alerta, computadores e notebooks com sintetizadores de voz para } \\
\text { usuários com deficiência realizarem suas pesquisas e acessarem a internet. } \\
\text { Áudio livro, livro em braille, livro ampliado, gravação de livro falado. }\end{array}$ \\
\hline $\begin{array}{l}\text { PINHEIRO e } \\
\text { OLIVEIRA (2018) }\end{array}$ & $\begin{array}{l}\text { Impressora braile, lupa eletrônica, cotejamento e correção de material } \\
\text { bibliográfico, conversão de material para formato acessível; apoio na leitura } \\
\text { de textos impressos à tinta; descrição de imagens; pesquisa na internet e } \\
\text { disponibilidade de computadores com leitores de tela e o Sistema } \\
\text { Operacional DOSVOX, leitores de tela como o NVDA, }\end{array}$ \\
\hline $\begin{array}{l}\text { WELLICHAN e LINO } \\
\text { (2018) }\end{array}$ & $\begin{array}{l}\text { Livros falados, em fonte ampliada em braile ou, livros digitalizados, } \\
\text { parcerias com instituições especializada, audiodescrição. } \\
\text { Equipamentos e programas, sendo: Ampliadores e leitores de tela, } \\
\text { sintetizador de voz, impressoras e conversores Braille, software Daysy para } \\
\text { leitura de materiais em formatos acessíveis }\end{array}$ \\
\hline MARTINS (2019) & $\begin{array}{l}\text { Coleções com literatura infanto-juvenil que inclua público com deficiência, } \\
\text { de livros impressos, em braille, e livro eletrônico (ebooks) e outras } \\
\text { tecnologias assistivas, formato: livros (em formato impresso e/ou } \\
\text { eletrônico), livro português/braile, e em formato com recursos de } \\
\text { acessibilidade: audiolivro, Descrição das Imagens, Legendas, Daisy com } \\
\text { voz humana, Daisy com voz sintética, Leitura Fácil, TXT, Leitura Ampliada, } \\
\text { Leitura Ampliada com contraste e PDF. }\end{array}$ \\
\hline
\end{tabular}

Fonte: Dados da pesquisa (2020)

Podemos perceber que alguns recursos estão presentes em diversos estudos como o Braille, os sistemas e softwares. O gráfico 1 apresenta os recursos mais citados nas publicações. 
Ana Cristina de Almeida Costa e Tania Chalhub

Gráfico 1 - Recursos mais utilizados para acessibilidade a deficientes visuais em bibliotecas

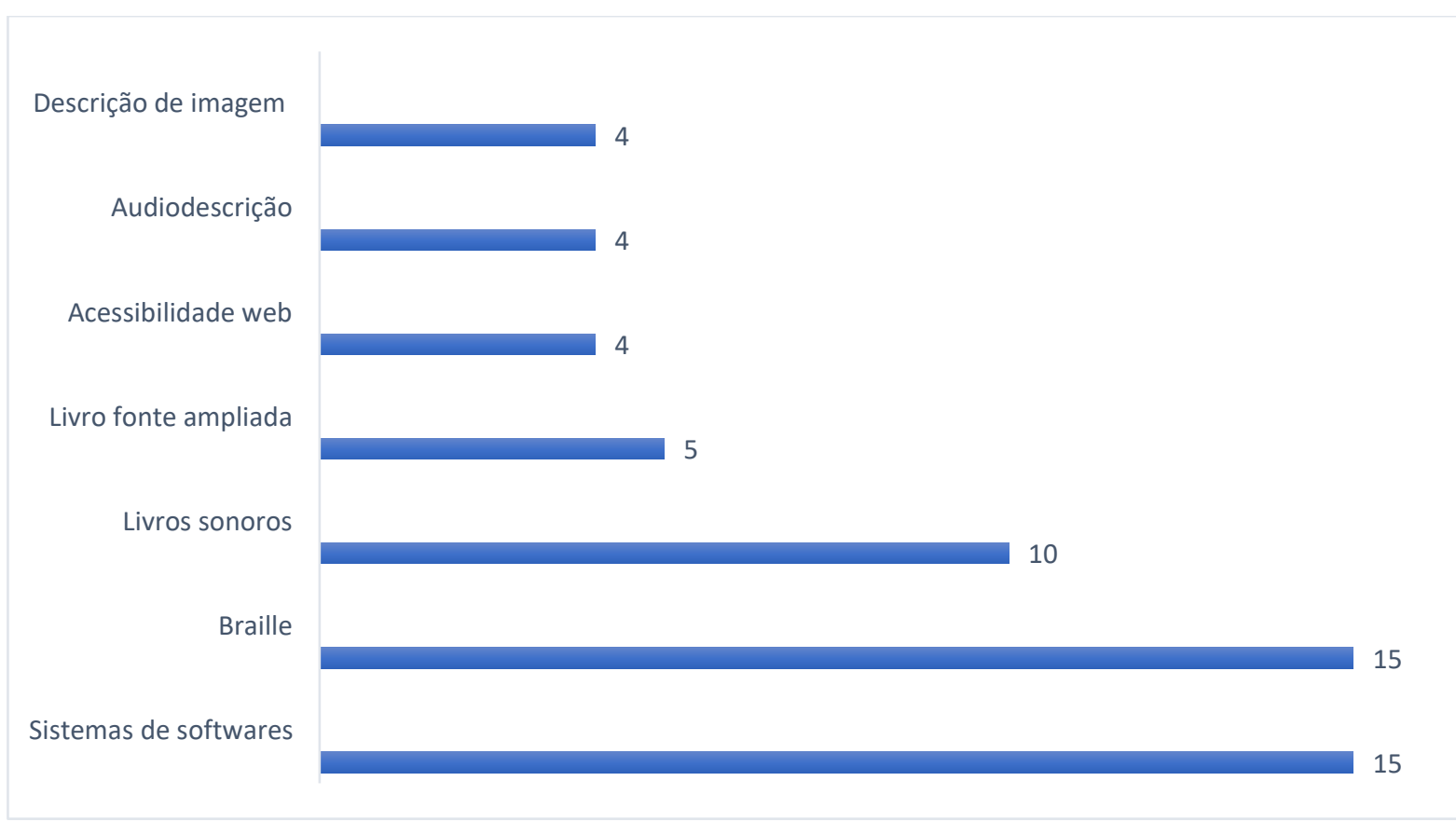

Fonte: Dados da pesquisa (2020).

Entre os recursos mais apontados como importante TA para alunos com deficiência visual temos os sistemas softwares, Braille e áudio livro. Vale ressaltar que a referência à sistemas e software e Braille engloba tudo o que faz correlação com estes. Por exemplo, em sistemas e software* foram citados: Sistema com síntese de voz: Jaws, Virtual Vision, DOSVOX, Dolphin, Slimware Window Bridge, Windows-Eyes, MecDayse; Sistemas de ampliação: Dolphin, SmartView, Magic, LentePro, softwares leitores de tela ou sintetizadores de voz, a ampliação de tela, lupa, contraste, leitor de tela, softwares LianeTTS, VoiceOver; ZoomText, Talks\&amp, Zooms, Google Talk Back e VoiceOver;

Em Braille foram citados: sinalização em braile em locais de circulação, acervo em braile, máquina de escrever em braile, impressora braile, livros formatados para impressão braile, entre outros. Em relação aos livros sonoros, são os que se refere aos livros em Daisy, audiolivro, audiobook e livro falado que podem ser mais bem explicados no link a seguir do site "Bengala Legal” Livros sonoros: audiolivro, audiobook e livro falado. | Bengala Legal.

Após mapeamento dos estudos de diversos autores 15 artigos foram selecionados e após análise dos conteúdos dos artigos, extraímos os recursos de acessibilidade e das tecnologias assistivas apresentadas nos estudos e descrevemos aqui os que consideramos relevantes a serem implementados também numa biblioteca escolar.

Algumas características dos principais recursos apontados pelos autores estudados: 
O uso das tecnologias assistivas na mediação da informação em biblioteca escolar: acessibilidade para alunos com deficiência visual

- Leitores de tela que associado aos sintetizadores de voz favorecem a leitura da tela do computador a exemplo de alguns softwares gratuitos como: o NonVisual Desktop Access - NVDA, leitor de tela livre, aberto e portátil para a Microsoft Windows, que não há necessidade de ser instalado, podendo ser salvo em um disco removível; Dosvox que é um software gratuito e de baixo custo, completo rodando em ambiente Windows que se comunica com o usuário através de síntese de voz e o auxilia em diversas tarefas no computador, tem boa recomendação para crianças, jovens e iniciantes em computadores;

- Mec Daisy: conjunto de programas que converte texto em áudio, de fácil acessibilidade, produz livros digitais e reprodução em áudio, gravado ou sintetizado. A leitura é acessada sob forma de áudio e texto digital. O tocador Mecdaisy toca livros em formato DAISY.

Foram relacionados também programas de computador leitor de tela Jaws, que lê ou dispõe em Braille todo o texto que estiver presente na tela do computador, possibilita acessar internet e escrever documentos.

Além dos recursos apresentados também foi apontada por alguns autores a lupa composta por lentes convergentes e que pode ser manual e horizontal. Seu uso é como o de uma régua eletrônica que amplia textos em cinco vezes e diminui as distorções, viabilizando a visualização das palavras. Possui auxílios não ópticos que nem sempre precisam usar lentes e pode ser utilizada com controle de iluminação a partir do uso das lâmpadas adequadas, para melhor desempenho visual dos usuários com visão subnormal, os quais necessitam de níveis diferentes de iluminação. Há também um serviço que pode ser oferecido que é a solicitação de pesquisas que poderão ser respondidas por e-mail gratuitamente.

Como visto em Gonçalves (2012) outros recursos são: a Ampliação de letras nos materiais impressos, caderno com pautas ampliadas, além de Canetas porosas e lápis macio 3 b ou 6 b para o aumento do contraste e caneta hidrográfica que tem contraste mais elevado. Há ainda tintas em alto relevo que contornam a figura e podem ser tocadas com dedo após secar.

Os meios de comunicação visual também podem ser facilitados através da descrição de imagens. Eles foram vistos em Araújo (2017) e Pinheiro e Oliveira (2018) como um recurso de acessibilidade comunicacional que descreve textualmente as imagens para facilitar que as 
TA leiam os conteúdos dessas imagens. Portanto, o recurso de descrição de imagens deve ser utilizado pela biblioteca como serviço de acessibilidade, sobretudo nas redes sociais e sites da biblioteca.

O uso das hashtags: \#PraCegoVer, \#PraTodosVerem \# e PraTodoMundoVer está sendo muito usado para descrição das imagens, com o objetivo de mostrar que é para todos, além de ser também uma maneira de chamar a atenção para a acessibilidade web.

Outro recurso mencionado na literatura por alguns autores (ARAÚJO, 2017; MARTINS, 2019; MELO, 2015; WELLICHAN; LINO, 2018) são os livros acessíveis: livro digital e livros formatados para impressão Braille que podem ser usados por leitores que saibam usar o sistema Braille; Áudio livro (livro falado), recurso que apresenta o conteúdo narrado em voz alta, por voz humana ou sintentizador e gravados em CD, DVD ou MP3, MP4, M4a, WMA, Ogg e outros e Livros no formato Daisy reproduzido pelo tocador Mecdaisy. Destaca-se que estas TA podem ser em versão paga, mas também podem ser baixados gratuitamente e disponibilizado por inúmeros repositórios e sites. Além desses também temos os livros com letras ampliadas, podendo ser em formato impresso ou digital. Eles apresentam fonte ampliada que facilita a leitura por usuários com baixa visão. Em formato digital temos os E-books os quais podem ser usados em computadores, tabletes, smarthphones, sendo a distribuição mais fácil e acessível em relação aos tradicionais. Aliado a um software ele pode ser transformado do digital para braile, fontes ampliadas e livro falado.

Outra questão considerável para uma biblioteca escolar inclusiva, como mostrado nos estudos de Poty et al. (2012) são os pisos táteis direcionais e sinalização braille, que fornecem sinalização às pessoas com deficiência visual, dando a esta maior independência no deslocamento. Isto precisa-ser visto como algo que faz parte, e não como uma obrigação.

Ressalta-se que há formatos que não requerem um grande investimento para instalação e manutenção, mas os benefícios trazem segurança e autonomia aos usuários. Assim, podem ser aplicados nas bibliotecas escolares. Outra questão importante segundo Gonçalves (2012) é disponibilizar computadores e/ou notebooks com leitor de tela, programa que interage com Sistema Operacional transformando texto em fala através dos sintetizadores de voz, para usuários com deficiência realizarem suas pesquisas e acessarem a internet.

Observamos com a análise dos estudos e concordamos com as proposições em que os autores fazem referência a importância da capacitação dos profissionais da biblioteca para 
saber lidar com os recursos e conhecer as limitações dos usuários cegos e os com baixa visão, a fim de realizar a mediação da informação. Além disso, é importante que a biblioteca disponha de computadores com internet.

Nessa perspectiva Araújo (2017) destaca que é relevante a capacitação dos bibliotecários para aprender a utilizar as ferramentas que proporcionam conteúdos acessíveis. Oliveira e Silva (2015) reforçam esse entendimento ao frisar que antes de inserir a TA na biblioteca, se faz necessário a capacitação do bibliotecário, que também deverá juntamente com demais profissionais, mapear as necessidades dos usuários e a partir de então desenvolver as práticas e adquirir os recursos de acessibilidade.

Os estudos fazem alusão ainda à necessidade de busca de parcerias interinstitucional. Existem projetos que confeccionam essas tecnologias de forma manual, então a parceria é significante uma vez que as questões de investimentos são bastante tímidas nas bibliotecas, o que acaba por limitar ainda mais a inclusão. Nesse sentido Alves (2017) ressalta que as bibliotecas para terem bons resultados devem trabalhar em conjunto com instituições e profissionais que atuam com a educação especial e inclusiva, recebendo um norte para melhor disponibilizar a acessibilidade. Todas essas questões aqui tratadas nos remetem ao objetivo de buscar recursos de acessibilidade que podem ser adotados nas bibliotecas escolares, para que estas contribuam no processo educacional, na formação cultural e principalmente na vida profissional dos alunos com deficiência visual.

As tecnologias assistivas em grande parte tem custos elevados, mas tem muitas que estão sendo disponibilizadas de forma gratuita. Portanto, agregar seus usos na biblioteca significa democratizar o direito de acesso à informação. 


\section{Considerações finais}

As análises dos artigos citados permitem ver o quão importante é o papel das tecnologias assistivas para mediação da informação nas bibliotecas. Com o uso destas é possível proporcionar maior independência dos usuários com deficiência visual.

Sabemos que a falta de investimentos nas bibliotecas escolares pode ser um fator limitante, por isso a importância de fazer parcerias com as instituições especializadas, para ver o que podem disponibilizar de forma gratuita. O profissional precisa ser resiliente e, mesmo que, na biblioteca em que atua não tenha como fazer aquisição por compra de todos esses recursos, ele pode buscar vários sites, que norteiam os profissionais como atuar com essa questão, além de haver software e livros para download gratuitos, tais como: Braille, ampliação de tela, softwares Dosvox, Virtual Vision, Magic, MecDayse, Delt Talk, leitores de tela NVDA e síntese de fala, livro em braile, livros falados e ampliados, descrição de imagens, recursos de software como leitores de tela ou sintetizadores de voz, a ampliação de tela e o contraste, impressora em relevo, ou thermoform, leitor de tela, detector de luminosidade, caneta para desenho em relevo, audiodescrição, audiolivro, ledor, rotuladora braile, sistema Dosvox, softwares LianeTTS, VoiceOver; ZoomText, ferramentas Talks\&Zooms e Google Talk Back.

Espera-se que o estudo traga contribuições para os profissionais da informação e para o desenvolvimento de outras pesquisas científicas. Sabe-se que a questão da inclusão ainda precisa e muito alavancar, tanto em nível de pesquisas com produção de artigos científicos, e muito mais na prática. Para isso é preciso derrubar o paradigma do preconceito e promover a acessibilidade atitudinal em primeiro lugar. Dessa forma, pode-se aumentar o protagonismo e autonomia dos alunos com necessidades educacionais especiais. 
O uso das tecnologias assistivas na mediação da informação em biblioteca escolar: acessibilidade para alunos com deficiência visual

\section{Referências}

ALMEIDA JÚNIOR, O. F.; BORTOLIN, S. Mediação da informação e da leitura. Londrina: s. n., 2007. Disponível em: http://eprints.rclis.org/13269/. Acesso em: 18 nov. 2020.

ALVES, T. L. Biblioteca acessível: eliminando barreiras. Revista Brasileira de Biblioteconomia e Documentação, São Paulo, v. 13, n. esp., p. 1883-1898, 2017. Disponível em: http://hdl.handle.net/20.500.11959/brapci/561. Acesso em: 18 nov. 2020.

ARAÚJO, A. K. S. O livro acessível: um auxiliar no acesso à informação para deficientes visuais. Revista Informação na Sociedade Contemporânea, Natal, v. 1, n. 2, p. 1-25, 2017. Disponível em: http://hdl.handle.net/20.500.11959/brapci/66079. Acesso em: 27 nov. 2020.

BRASIL. Lei no 13.146, de 06 de julho de 2015. Institui a Lei Brasileira de Inclusão da Pessoa com Deficiência (Estatuto da Pessoa com Deficiência). Brasília, DF, 2015. Disponível em: http://www.planalto.gov.br/ccivil_03/_ato2015-2018/2015/lei/113146.htm. Acesso em: 19 nov. 2020.

CONTE, E.; OURIQUE, M. L. H.; BASEGIO, A. C. Tecnologia assistiva, direitos humanos e educação inclusiva: uma nova sensibilidade. Educação em Revista, Belo Horizonte, v. 33, p. 1-24, 2017. Disponível em: http://www.scielo.br/scielo.php?script=sci_arttext\&pid=S010246982017000100140\&lng=pt\&nrm=iso. Acesso em: 27 jan. 2021.

DINIZ, I. C. D. S.; ALMEIDA, A. M. P.; FURTADO, C. C. Bibliotecas universitárias inclusivas: acessibilidade e oportunidades para os usuários com necessidades especiais. Revista Brasileira de Biblioteconomia e Documentação, São Paulo, v. 13, n. esp., p. 17581780, 2017. Disponível em: http://hdl.handle.net/20.500.11959/brapci/2919. Acesso em: 27 jan. 2021

ESTABEL. B.; MORO, E. L. S. A mediação da leitura na família, na escola e na biblioteca através das tecnologias de informação e de comunicação e a inclusão social das pessoas com necessidades especiais. Inclusão Social, Brasília, v. 4, n. 2, p. 67-81, dez. 2011. Disponível em: http://revista.ibict.br/inclusao/article/view/1657. Acesso em: 19 nov. 2020.

FIALHO, J.; SILVA, D. O. Informação e conhecimento acessíveis aos deficientes visuais nas bibliotecas universitárias. Perspectivas em Ciência da Informação, Belo Horizonte, v. 17, n. 1, p. 153-168, 2012. Disponível em: http://hdl.handle.net/20.500.11959/brapci/37823. Acesso em: 24 nov. 2020.

FERNANDES, N. L.; VIANNA, W. B. Percepção de deficientes visuais quanto à tecnologia assistiva e os softwares de síntese de voz para uso em bibliotecas. Pesquisa Brasileira em Ciência da Informação e Biblioteconomia, João Pessoa, v. 11, n. 2, p. 1- 18, 2016. Disponível em: http://hdl.handle.net/20.500.11959/brapci/31131. Acesso em: 24 nov. 2020

GONÇALVES, E. F. P. As tecnologias assistivas e a atuação do bibliotecário como intermediário entre as fontes de informação e o deficiente visual. Múltiplos Olhares em Ciência da Informação, Belo Horizonte, v. 2, n. 1, p. 1- 9, 2012. Disponível em: http://hdl.handle.net/20.500.11959/brapci/81259. Acesso em: 26 nov. 2020. 
HOTT, D. F. M.; RODRIGUES, G. M.; OLIVEIRA, L. P. Acesso e acessibilidade em ambientes web para pessoas com deficiência. Brazilian Journal of Information Science, Marília, v. 12, n. 4, p. 45-52, 2018. Disponível em:

https://revistas.marilia.unesp.br/index.php/bjis/article/view/8318. Acesso em: 27 jan. 2021.

MALHEIROS, T. M.; CUNHA, M. B. As bibliotecas como facilitadoras no acesso à informação por usuários com deficiência visual. Revista Digital de Biblioteconomia \& Ciência da Informação, Campinas, v. 16, n. 1, p. 146-170, jan./abr. 2018. DOI: 10.20396/rdbci.v16i1.8650318. Disponível em: https://periodicos.sbu.unicamp.br/ojs/index.php/rdbci/article/view/8650318/pdf. Acesso em: 26 nov. 2020.

MARCOLINO, M. A. R.; CASTRO FILHO, C. M. O bibliotecário na biblioteca escolar e os usuários especiais: o desafio da inclusão. Revista Brasileira de Biblioteconomia e Documentação, São Paulo, v. 10, n. Esp., 2014. Disponível em: http://hdl.handle.net/20.500.11959/brapci/1278. Acesso em: 19 nov. 2020.

MELO, R. S. F. Formação de acervos acessíveis em bibliotecas universitárias: o caso da biblioteca central Zila Mamede. Bibliocanto, Natal, v. 1 n. 1, p. 31- 44, dez. 2015. Disponível em: http://hdl.handle.net/20.500.11959/brapci/120228. Acesso em: 20 nov. 2020.

MARTINS, L. M. B. A coleção da biblioteca escolar e acessibilidade: o processo de seleção de livros de literatura infantil e juvenil. Convergência em Ciência da Informação, Aracaju, v. 2, n. 3, p. 29-68, set./dez. 2019. Disponível em:

http://hdl.handle.net/20.500.11959/brapci/140478. Acesso em: 20 nov. 2020.

MATOS, E. J. S.; LEMOS, R. B. S.; SILVA, J. L. As tecnologias assistivas para a educação na biblioteca pública Benedito Leite. Revista Bibliomar, São Luís, v. 16, n. 1, p. 36-51, jan./jun. 2017. Disponível em: http://hdl.handle.net/20.500.11959/brapci/126323. Acesso em: 26 nov. 2020.

OLIVEIRA, G. D.; SILVA, E. F. Bibliotecas e bibliotecários em busca da acessibilidade. Bibliocanto, Natal, v. 1 n. 1, p. 68-86, 2015. Disponível em: http://hdl.handle.net/20.500.11959/brapci/120235. Acesso em: 26 dez. 2020.

PINHEIRO, A. L.; OLIVEIRA, H. V. Tecnologia assistiva no processo de mediação da informação aos usuários com deficiência visual em biblioteca universitária. In: ENCONTRO NACIONAL DE PESQUISA EM CIÊNCIA DA INFORMAÇÃO, 19., 2018, Londrina. Anais [...]. Londrina: UEL, 2018. p. 2108-2116. Disponível em: http://hdl.handle.net/20.500.11959/brapci/102315. Acesso em: 24 nov. 2020.

POTY, E. P. et al. Acessibilidade: adequação das bibliotecas universitárias de Teresina aos portadores de deficiência visual. In: ENCONTRO NACIONAL DE ESTUDANTES DE BIBLIOTECONOMIA, DOCUMENTAÇÃO, CIÊNCIA DA INFORMAÇÃO E GESTÃO DA INFORMAÇÃO, 35., 2012, Belo Horizonte. Anais [...]. Belo Horizonte: UFMG, 2012. p.1-17. Disponível em: http://hdl.handle.net/20.500.11959/brapci/70368. Acesso em: 24 nov. 2020.

SANTOS, K. G. D.; CARVALHO, K. A. Acessibilidade e tecnologia assistiva em bibliotecas universitárias: estudo de caso no centro federal de educação tecnológica de Minas Gerais. 
O uso das tecnologias assistivas na mediação da informação em biblioteca escolar: acessibilidade para alunos com deficiência visual

Revista Ibero-Americana de Ciência da Informação, Brasília, v. 13, n. 1, p. 5-19, jan./abr. 2020. Disponível em: https://periodicos.unb.br/index.php/RICI/article/view/22362/25333. Acesso em: 30 nov. 2020.

SILVA, A. J. M.; DUARTE, F. E. G.; SILVA, J. L. C. Mediação da informação em biblioteca escolar: um estudo realizado na biblioteca Madre Paula do Colégio Santa Teresa de Jesus. Revista Brasileira de Biblioteconomia e Documentação, São Paulo, v. 13, n. esp., p. 788802, 2017. Disponível em: http://hdl.handle.net/20.500.11959/brapci/3249. Acesso em: 20 nov. 2020.

SILVA, H. O. P. E.; BARBOSA, J. S. A relação deficiente visual e biblioteca universitária: a experiência do centro de atendimento ao deficiente visual - Cadv da Universidade Federal de Minas Gerais. Múltiplos Olhares em Ciência da Informação, Belo Horizonte, v. 1, n. 1, p. 1-17, mar. 2011. Disponível em: http://hdl.handle.net/20.500.11959/brapci/61719. Acesso em: 26 nov. 2020.

SILVA, L. S.; MENEZES, E. M. Metodologia da pesquisa e elaboração de dissertação: manual de orientação. Florianópolis: Laboratório de ensino à distância da UFSC, 2001. Disponível em: http://cursos.unipampa.edu.br/cursos/ppgcb/files/2011/03/Metodologia-daPesquisa-3a-edicao.pdf. Acesso em: 20 nov. 2020.

STORTI, V. R. et al. Promover a acessibilidade aos deficientes visuais e baixa visão à rede de bibliotecas da UNESP. Revista Brasileira de Biblioteconomia e Documentação, São Paulo, v. 10, n. esp., 2014. Disponível em: http://hdl.handle.net/20.500.11959/brapci/4497. Acesso em: 26 nov. 2020.

WELLICHAN, D. S. P.; LINO, C. C. T. S. A biblioteca escolar no contexto da inclusão: como oferecer e vivenciar experiências inclusivas nesse ambiente. Biblionline, João Pessoa, v. 14, n. 1, p. 3-16, 2018. Disponível em: http://10.22478/ufpb.1809-4775.2018v14n1.40603. Acesso em: 26 nov. 2020

WELLICHAN, D. S. P.; LINO, C. C. T. S. Aprender, ensinar e praticar: a biblioteca escolar como recurso estratégico para inclusão de pessoas com deficiências. Revista Bibliomar, São Luís, v. 19, n. 1, p. 141-158, 2020. Disponível em:

http://hdl.handle.net/20.500.11959/brapci/141960. Acesso em: 26 nov. 2020.

Artigo submetido em: 22 abr. 2021.

Artigo aceito em: 15 maio 2021. 